\title{
EL EMPLEO DE LA EXCEPCIÓN DE ILEGALIDAD EN TODAS LAS JURISDICCIONES*
}

\author{
Cesar Augusto Saavedra Madrid***
}

\begin{abstract}
RESUMEN
Ese artículo analiza la excepción de ilegalidad en el ordenamiento jurídico colombiano, rastrea su creación y su antecedente francés. En este marco y empleando metodología cualitativa de fuentes jurisprudenciales, mayormente, estudia y caracteriza el acto administrativo reglamentario, objeto de la excepción, mostrando el error histórico en su tratamiento. La relectura de la excepción de ilegalidad permite, a partir de su verdadera naturaleza de instrumento de realización del principio de legalidad, aplicarla en las jurisdicciones civil, comercial, laboral, penal y disciplinaria dado el efecto exponencial que en materia de reglamentación trae aparejado el Estado Social de Derecho que, en tanto tal, puede igualmente emplearse en procesos adelantados por autoridades administrativas de naturaleza jurisdiccional. Para el efecto, se avanzan algunos puntos de un posible test.
\end{abstract}

* El presente artículo es inédito y es un producto aplicado de la investigación sobre núcleos de validez en teoría jurídica adelantado en la Maestría en Filosofía del Derecho Contemporáneo de la Universidad Autónoma de Occidente y que continúa como proyecto en el doctorado. Dicha investigación tiene como propósito general plantear una solución razonable a las dificultades que la transformación del ordenamiento jurídico, por la irradiación de la Constitución condicionando la legislación, la jurisprudencia, la acción de los actores políticos y las relaciones sociales -lo que Guastini llamó la constitucionalización del ordenamiento jurídico- presenta cuando entran en juego derechos fundamentales laborales en la jurisdicción contenciosoadministrativa. La dogmática administrativa se enfrenta a la dogmática constitucional dando lugar a tratamientos inadecuados y contradictorios.

* Licenciado en Filosofía de la Universidad del Valle. Abogado de la Universidad Santiago de Cali. Especialización en Derecho Administrativo de las Universidades Pontificia Bolivariana y San Buenaventura. Especialización en Derecho Constitucional y en Derecho Laboral de la Universidad Libre y Especialista en Derecho Comercial de la Universidad Icesi. Magister en Filosofía del Derecho Contemporáneo de la Universidad Autónoma de Occidente. Estudiante de Doctorado en Derecho -II Semestre-, Universidad Santo Tomás. 
Palabras clave: Excepción de ilegalidad, acto administrativo reglamentario, principio de legalidad, Estado Social de Derecho.

\begin{abstract}
This article analyzes the plea of illegality in the Colombian legal system, tracing its creation and its French antecedent. In this context and using qualitative methodology jurisprudential sources, mostly, study and characterizes the regulatory administrative act, the exception object, showing the historical mistake in their treatment. The reading of the plea of illegality allows, from its very nature as an instrument of realizing the principle of legality, in jurisdictions applying civil, commercial, labor, criminal and disciplinary given the exponential effect on regulation brings the State social law which, as such may be used in proceedings by administrative authorities of a judicial nature. To the end, move some points of a possible test.
\end{abstract}

Key words: Plea of illegality, regulatory administrative act, principle of legality, State social law.

\title{
INTRODUCCIÓN
}

Definida como control indirecto de validez normativa sobre el acto administrativo reglamentario, la excepción de ilegalidad es de las figuras más emblemáticas y de las menos estudiadas. El grueso de sus críticas apuntaron en buena parte a su existencia: unos aseguraron que existió ${ }^{1}$ pero desapareció con la expedición de la Constitución de 1991 (en adelante C/1991) porque el art. 12 de la ley 153 de $1887^{2}$ se dirigía a la aplicación de la Constitución de 1886 (en adelante C/1886). Otros la negaron ${ }^{3}$ ofreciendo dos argumentos: a) la posibilidad otorgada a de la jurisdicción contenciosa con la ley 130 de $1913^{4}$ de decidir en torno a la legalidad del acto administrativo reglamentario puede ocurrir en cualquier tiempo y b) razones de conveniencia porque el que los funcionarios antepusieran su discernimiento a los de la suprema autoridad administrativa frente a la ejecución de normas administrativas produciría confusión jurídica y desarticularía la tarea de la rama ejecutiva, a la vez que la despojaría de su carácter jerárquico y operativo.

1 CHARRY, J. La excepción de inconstitucionalidad. Primera Edición. Bogotá. Ediciones Jurídicas Radar. 1994, p. 176.

2 República de Colombia, Consejo Nacional Legislativo. Ley 153 del 24 de agosto de 1887 (que adiciona y reforma los Códigos nacionales, la ley 61 de 1886 y la ley 57 de 1887).

3 VIDAL, J. Derecho Administrativo. Decima Primera Edición. Editorial Temis. Bogotá. 1997, p. 386.

4 República de Colombia. Congreso de Colombia. Ley 130 del 13 de Diciembre de 1913 (sobre la jurisdicción de lo contencioso administrativo). 
Admitida su existencia ${ }^{5}$, se cuestionó ${ }^{6}$ que el fallo no tuviera al art. 4. (C/1991) como su fundamento.

El presente trabajo tuvo como insumo básico algunas jurisprudencias del Consejo de Estado, varias de la Corte Constitucional y alguna de la Corte Suprema, por ser la excepción de ilegalidad una construcción jurisprudencial. La metodología cualitativa de las fuentes se centró en el análisis del discurso, lectura que permitió rastrearla ubicando categorías identificadas como relevantes, tales como el acto administrativo reglamentario o el enfoque que desde el inicio se le dio. Pronto se advirtió un tratamiento impreciso y equivoco en relación con su alcance, entre otras cosas confundiendo ilegalidad con invalidez, asumiendo que esta se deduce de la discordia entre el acto y la norma cuando en verdad lo que de ello se infiere es la presencia de una ilegalidad: la validez (invalidez) apuntó con certeza Nieto ${ }^{7}$, es resultado de una valoración. En Francia la excepción de ilegalidad responde al modelo de supremacía de la ley que expresa la voluntad general -Estado constitucional es aquél que asegura la primacía de la ley en el sistema de fuentes, art. 16, Declaración de derechos del Hombre y el Ciudadano-, modelo al que respondíamos originalmente -el art. 4 del Código Civil ${ }^{8}$ define la ley como "una declaración de voluntad soberana"-, y que coexistía con el norteamericano de supremacía de la Constitución, iniciada como supremacía legal con el juez Coke en el sistema inglés ${ }^{9}$ quien, apoyándose en el iusnaturalismo defendió la superioridad de la Constitución inglesa frente al Rey y el Parlamento, argumento que finalmente implicará que la voluntad del pueblo es superior a la de sus órganos ${ }^{10}$.

5 República de Colombia. Corte Constitucional, Sala Plena. Sentencia C-037 del 26 de Enero de 2000. M.P. Vladimiro Naranjo Mes. Expediente D 2441.

6 ROJAS, D. “¿Abolida la excepción de ilegalidad?” En: Pensamiento Jurídico No. 12. 2000. Bogotá. Revista de la Universidad Nacional, Facultad de Derecho, Ciencias Políticas y Sociales. Editorial de la Universidad, pp. 209-220.

7 NIETO, A. "Estudio preliminar". En: BALADIEZ, M. Validez y eficacia de los actos administrativos. Primera Edición. Madrid. Marcial Pons, Ediciones Jurídicas. 1994, p. 49.

8 República de Colombia. Consejo Nacional Legislativo. Código Civil de la Nación, sancionado el día 26 de Mayo de 1873 y adoptado por el art. 1 de la Ley 57 del 15 de Abril de 1887.

9 ARAGÓN, M. Sobre las nociones de supremacía y supralegalidad Constitucional. Primera Edición. Bogotá. Universidad Externado. Editorial de la Universidad. 1986, pp. 18-20.

10 Para el juez Coke, si la Constitución consagraba la exigencia de que los tributos fueran aprobados por los representantes de quienes los soportaban, no teniendo los colonos representación en el Parlamento inglés no estaban obligados a sufragarlos. Este argumento que mutó hacia las doctrinas iusnaturalistas del pacto social (Locke) terminó negando la competencia de la Corona inglesa sobre las colonias en virtud de los derechos del pueblo americano: por encima de los poderes del Estado están los derechos de los hombres, base teórica de la supralegalidad constitucional que, como anota Aragón, no es otra que el genuino concepto de Constitución: la limitación de los poderes del Estado está encaminada a garantizar la libertad de los ciudadanos. 
La excepción de ilegalidad nació entre nosotros con un fallo que subsiguientes reconfiguraron sin lograr articular el modelo francés al que responde nuestro contencioso administrativo con la primacía de la Constitución, a fortiori que en la práctica oscilamos entre ambas epistemes: ni desapareció el europeo ni se impuso totalmente el norteamericano. Las decisiones fijaron un rumbo que anuló las potencialidades de la excepción de ilegalidad despojándola de sus características operativas, hecho del cual emergió el problema jurídico cuya pregunta interroga por el alcance de la figura, así como de su hipótesis de trabajo: precisar el error y restablecer el papel de la excepción de ilegalidad como dispositivo del principio de legalidad, proporcionando un fundamento que permita articular y materializar su uso en las distintas jurisdicciones.

\section{El ACTO ADMINistrativo REgLAMENTARIO}

El acto administrativo, producto de la función administrativa, está dirigido a la aplicación de la Constitución, la Ley y los ordenamientos inferiores. Es un acto jurídico de naturaleza especial en cuanto determina de antemano el sentido en que debe ejecutarse la norma de derecho en el caso individual. Por ser el acto administrativo reglamentario el objeto de la excepción de ilegalidad, este capítulo hace un bosquejo general para, a renglón seguido, reconstruir su creación en la jurisprudencia contenciosa administrativa y dar cuenta de los elementos que lo componen.

En Colombia, la función administrativa tuvo desde sus inicios acento organicista. Entre el órgano, la función y el acto administrativo existe tal relación que la Ley 167 de $1941^{11}$ identificó el acto administrativo con el acto de la administración: los arts. 62 y ss., enumeraron los actos administrativos acusables en "razón del sujeto que los expide". Años más tarde, el Consejo de Estado ${ }^{12}$ varió la óptica: consideró el contenido -y el objetivo- de la voluntad administrativa-distinta de la opinión del funcionario en el caso particular ${ }^{13}$-, considerándolo elemento esencial para la validez porque producir efectos jurídicos es lo que busca con el acto. Los administrativistas efectuaron espesas consideraciones en torno a los aspectos externos -forma- e internos -sustancia-, de cara a su existencia y validez, sin perder de vista la eficacia, distinguiendo al efecto dos momentos ${ }^{14}$ la decisión -en el interior de la administración- y la exteriorización - mediante la comunicación, notificación,

11 República de Colombia. Poder Público - Órgano Legislativo Nacional. Ley 167 del día 24 de Diciembre de 1941 (sobre organización de la jurisdicción Contencioso-administrativa).

12 República de Colombia. Consejo de Estado. Sección Cuarta. Sentencia (sin número) del día 13 de Diciembre de 1976. Consejero Ponente: Jorge Dávila Hernández. Expediente 4.608.

13 República de Colombia. Consejo de Estado. Sección Cuarta. Sentencia (sin número) del día 13 de Diciembre de 1976. Consejero Ponente: Jorge Dávila Hernández. Expediente 4.608.

14 República de Colombia. Consejo de Estado. Sin Sección. Sentencia (sin número) del día 30 de Octubre de 1964. Consejero Ponente: Carlos Gustavo Arrieta. Expediente 1.524. 
publicación o ejecución-, construcción en la que se desarrollaron teorías en torno a los vicios. Así, siendo el acto administrativo un acto jurídico, la existencia y validez se analizaron con cargo al art. 1.502 del Código Civil -capacidad, voluntad, objeto y causa lícita- y casi terminaron semejándose. Para algunos, a la validez debía incorporarse la materia especifica de que trata el acto administrativo porque él tiene un complemento: el art. 1.501 íb (elementos esenciales), vía por la que la competencia, la forma y el contenido resultaron elementos preponderantes.

El análisis de la competencia se consideró desde el art. 63 (C/1886) y su afirmación de que todo empleo tiene funciones detalladas ley o reglamento, sendero de análisis doctrinal y jurisprudencial por el que se auscultaron vicios como la carencia de investidura (funcionario de hecho, usurpador, etc.) y obrar fuera de las atribuciones (vía de hecho, invasión de competencia, etc.), entre otros. Se agrega que siendo la capacidad -de la persona humana- al derecho civil lo que la competencia-del funcionario- al derecho administrativo, órgano y competencia se confunden: la capacidad -habilitación de la potestad- la otorga la ley y su ejercicio se presume ajustado a ella en virtud del principio de legalidad y sus notas de obligatoriedad, imperatividad y oponibilidad, presunción de legalidad que implica que el acto administrativo, una vez expedido tiene contenido auténtico ${ }^{15}$, resultando perfecto -válido y eficaz- y en tanto tal, legítimo: no requiere declaración judicial ni puede nulitarse de oficio.

Si bien es propio del acto administrativo ejecutar la ley, en ocasiones las notas generales, impersonales y abstractas dificultan o imposibilitan hacerlo en forma directa e inmediata requiriéndose reglamentación previa. En esta perspectiva establecía en su versión primigenia el art. 25 del Código Civil que la interpretación con autoridad era del legislador -el art. 26 calificaba de doctrinaria la interpretación de los jueces y funcionarios públicos- por mandato del art. 76.1 (C/1886) -a la que se agregaba la que realizaba el Gobierno al expedir decretos con fuerza de ley ${ }^{16}-$, no obstante se consideró que existía otra interpretación: la que nacía de los reglamentos expedidos por el órgano ejecutivo -art. 120.3, C/1886-: "si la reglamentación es el primer paso en el camino de su aplicación, forzosamente tendrá que interpretarla [se refiere a la ley] para efectos de desenvolverla en el correspondiente decreto"17.

Esta doctrina se separó de la construcción que en torno al poder reglamentario hizo la Corte Suprema en 1928 pero compartió el que estuviese implícito en la necesidad y obligación del Gobierno de hacer cumplir las leyes: resultaba una atribución

15 República de Colombia. Consejo de Estado. Sin sección. Sentencia (sin número) del 12 de Abril de 1962. Consejero Ponente: Guillermo González Charry. Sin radicación.

16 República de Colombia. Consejo de Estado. Sección Segunda. Sentencia (sin número) del día 15 de Septiembre de 1977. Consejero Ponente: Samuel Buitrago Hurtado. Expediente 4.370.

17 República de Colombia. Consejo de Estado. Sin sección. Sentencia (sin número) del 22 de Marzo de 1963. Consejero Ponente: Carlos Gustavo Arrieta. Sin radicación. 
conferida por la Constitución donde la fuerza obligatoria del reglamento derivaba de la ley reglamentada en la que encontraba sus "limites naturales". Para la Corte Suprema, el poder reglamentario implícito si bien conllevaba la facultad de escoger medios no prohibidos y coherentes con la disposición, necesarios y adecuados a los fines, no comportaba expedir reglamentos autónomos dirigidos al cumplimiento de disposiciones constitucionales no desarrolladas por la ley, doctrina que provenía de la Corte Suprema norteamericana ${ }^{18}$, rectificada en un fallo de 1936 y a la cual sólo se aludió, incidentalmente, en 1941.

Necesitada la potestad reglamentaria del entendimiento y valoración de la ley para desplegar debidamente su contenido en el reglamento, la característica de imperatividad permitía tener su relación jurídica con la ley de manera similar a la existente entre la Constitución y la ley. La función reglamentaria exigía un proceso previo de análisis y evaluación indagando por los fines de la ley, auscultando el contenido general y los alcances parciales expresos e implícitos ${ }^{19}$. Viene de lo dicho que el fundamento del reglamento radica en la necesidad de ejecutar el derecho

18 República de Colombia. Consejo de Estado. Sección Cuarta. Sentencia (sin número) del 24 de Mayo de 1973. Consejero Ponente: Miguel Lleras Pizarro. Expediente 2.226:

"../ se inspiró en doctrina de la Corte Suprema de los Estados Unidos de América del Norte y en él se desarrolló la teoría de las facultades implícitas o incidentales, que la misma Corte resumió así:

"Son postulados de derecho constitucional generalmente reconocidos hoy y respaldado por altas autoridades, los siguientes:

"1. Todos los poderes del Estado que tienen atribuciones constitucionales para ejercer una función o la obligación de ponerla por obra, tienen también, de acuerdo con los dictados de la razón, la facultad de escoger los medios necesarios y adecuados a esos fines, siempre que no estén prohibidos y sean coherentes con la letra y el espíritu de la disposición constitucional a que acceden.

"2. En consecuencia, una facultad se considera implícita en la Constitución siempre que sea necesaria para dar efecto a una atribución conferida expresamente por ella misma.

"3. Todo aquello que se halle implícito en la Constitución forma parte de esta, de la misma manera que sus disposiciones expresas.

"4. Puede afirmarse, por tanto, que no existe en la Constitución atribución alguna de facultades que no entrañe y lleve consigo en su aplicación otras que, si bien tácitas, son vitales para las primeras y necesarias a su ejercicio".

Esta doctrina no ha sido repetida en ninguna otra sentencia de la Corte Suprema y al contrario, modificada y rectificada en el fallo de 7 de Octubre de 1936. Importa advertir que tuvo cuatro salvamentos de voto en los que, en esencia se comentó: /.../

En la sentencia de 21 de Febrero de 1941 incidentalmente se niega la existencia de los llamados reglamentos autónomos así: "La subordinación del poder reglamentario a la Ley y a la Constitución conlleva (sic) otra limitación que consiste en que el reglamento debe tener vida en una Ley existente, para desenvolver sus disposiciones. Por eso el dominio del poder reglamentario en razón de su subordinación es completar la Ley por disposiciones de detalle para asegurar y facilitar su ejecución".

19 República de Colombia. Consejo de Estado. Sin sección. Auto (sin número) del día 22 de Marzo de 1963. Consejero Ponente: Carlos Gustavo Arrieta. Sin radicación. 
objetivo y será tanta la materia reglamentable cuanta aparezca de la necesidad de aplicar la ley.

La potestad reglamentaria la confirió el art. 120.3 (C/1886) al Presidente de la República, suprema autoridad administrativa -basamento de la noción de poder jerárquico-, quien la ejercía expidiendo órdenes, decretos y resoluciones -los tres elementos de la reglamentación- necesarios para la cumplida ejecución de las leyes. El acto administrativo general resultante se tenía por ley en sentido material. Dicha facultad correspondía por paralelismo de formas ${ }^{20}$ a los alcaldes -y gobernadores-, excluyendo la reglamentación de la ley por estarle expresamente atribuida al Presidente de la República. Con cargo al paralelismo se derivaron facultades reglamentarias de poder de policía a los gobernadores, agentes del Gobierno y jefes de la administración seccional -art. 181, C/1886- y los alcaldes, a su vez agentes del gobernador y jefes de la administración municipal -art. 201, C/1886- ${ }^{21}$.

Siendo la función administrativa una actividad de ejecución y la función reglamentaria la consecuencia necesaria de aquella actividad, los decretos se dividieron en cinco categorías ${ }^{22}$ : decretos ley -art. 11, Ley 153 de 1887-, ordinarios fundados en autorización especial y expresa -art. 76.11, C/1886-, reglamentarios -art. 120.3, C/1886- y simplemente ejecutivos para ejercer algunas funciones constitucionales o legales como nombramiento de empleados, y los de intervención en materias económicas y sociales que introdujeron las enmiendas constitucionales de 1936 y $1945^{23}$, pues lo que antes se hacía "por medio de leyes" -art. 28, C/1886- se hizo "por mandato de la Ley".

20 República de Colombia. Consejo de Estado. Sin sección. Sentencia (sin número) del día 30 de Agosto de 1963. Consejero Ponente: Carlos Gustavo Arrieta. Sin radicación.

21 República de Colombia. Consejo de Estado. Sin sección. Sentencia del día 13 de Noviembre de 1962. Consejero Ponente: Gabriel Rojas Arbeláez. Expediente 2.132:

"Agente del Gobierno el Gobernador, y de éste el Alcalde, tienen ambos la función común de cumplir la Constitución, las leyes, las ordenanzas y los acuerdos, adoptando para ello las medidas correspondientes. Este es un campo de actividad propio del Órgano Ejecutivo, en el que la iniciativa del funcionario debe seguir la pauta que indica el reglamento superior, reglamento que no puede contemplar todos los hechos y situaciones, sino los conocidos y los que se pueden prever. Pero aparte y como derivación de la facultad que en el numeral 70 del artículo 120 de la Constitución Nacional se da al Presidente de la República, referente a la conservación y restablecimiento del orden público, queda un especial campo de actividad. En este último sí cabe la iniciativa particular, porque al orden que es el equilibrio de la vida social, lo puede afectar de varios modos el desorden, que es poliforme. Por lo mismo las medidas para conservar y restablecer aquél no se pueden catalogar. Esas medidas son las propias de las autoridades de Policía, y se caracterizan por su índole más autónoma. Así lo requiere la función de procurar la seguridad, la salubridad y la tranquilidad de los asociados".

22 República de Colombia. Consejero de Estado. Sin sección. Sentencia (sin número) del día 19 de Agosto de 1955. Consejero Ponente: Ildefonso Méndez. Sin radicación.

23 República de Colombia. Consejo de Estado. Sección Primera. Sentencia (sin número) del día 31 de Septiembre de 1966. Consejero Ponente: Alberto Hernández Mora. Sin radicación. 
Todo este insumo fue clasificado por el Consejo de Estado ${ }^{24}$. Así, la taxonomía del acto administrativo reglamentario consideró los reglamentos constitucionales, previamente definidos ${ }^{25}$ como aquellos que el Gobierno expide en desarrollo directo de la Constitución en los casos en que ella lo autoriza explícita o implícitamente, y reglamentos legales que son los que expide el órgano administrativo en desarrollo de una ley. Éstos, a su vez, habían sido clasificados ${ }^{26}$ en reglamento legal especial y reglamento legal corriente, fundándose la diferencia en los poderes jurídicos utilizados al expedir la ley, en los ejercitados por el órgano administrativo al reglamentarla y en la extensión o limitación del ejercicio de la facultad para proferirlos.

Al desplegarse la ley en el acto reglamentario, previa interpretación por ser razón del reglamento la necesidad de hacer eficaz la norma de derecho facilitando su inteligencia y cumplimiento, se debía considerar que el límite lo establecía "la misma Constitución a expedir los decretos necesarios 'para la cumplida ejecución de las leyes" "27. Desarrollar de manera pormenorizada y comprensiva el decreto reglamentario no podría implicar, por tanto, extender así, sin más, sus efectos. Aparecen los limites generales de la potestad reglamentaria: la necesidad de asegurar la aplicación adicionando lo estrictamente necesario y siempre que se desprenda del mandato porque lo que ya expresado torna el nuevo precepto en superfluo y si se adiciona o recorta el alcance más de lo debido se incurre en violación de las disposiciones superiores de derecho ${ }^{28}$, añadiéndose la competencia del órgano en la materia.

\section{LA EXCEPCIÓN DE ILEGALIDAD}

El control de legalidad del acto administrativo reglamentario le fue atribuido al Consejo de Estado con la ley 130 de 1913, norma que le permitía la revisión de los decretos acusados de ilegalidad. Por estar dirigida la excepción de ilegalidad a verificar la validez del acto administrativo reglamentario respecto de la ley reglamentada y los supuestos explícitos e implícitos, fines y contenido general y alcances parciales, este capítulo se ocupa de su génesis, alcance y características.

24 República de Colombia. Consejo de Estado. Sin sección. Sentencia (sin número) del día 28 de Junio de 1963. Consejero Ponente: Carlos Gustavo Arrieta. Sin radicación.

25 República de Colombia. Consejo de Estado. Sin sección. Sentencia del día 14 de Noviembre de 1962. Consejero Ponente: Carlos Gustavo Arrieta. Sin radicación.

26 República de Colombia. Consejo de Estado. Sin sección. Sentencia del día 10 de Octubre de 1962. Consejero Ponente: Carlos Gustavo Arrieta. Sin radicación.

27 República de Colombia. Consejo de Estado. Sin secciones. Sentencia (sin número) del día 14 de Abril de 1942. Consejero Ponente: Diógenes Sepúlveda Mejía. Sin radicación.

28 República de Colombia. Consejo de Estado. Sin sección. Sentencia (sin número) del día 17 de Febrero de 1962. Consejero Ponente: Carlos Gustavo Arrieta. Sin radicación. 
Del control de legalidad se excluían las ordenanzas departamentales -actos administrativos ${ }^{29}$ - y los acuerdos municipales -igualmente actos administrativos porque son expedidos "por entidades exclusivamente administrativas" 30 -, porque eran susceptibles de la acción de nulidad por mandato del art. 192 (C/1886) que dispuso que eran obligatorios mientras no fueran anulados o suspendidos por la jurisdicción de lo contencioso administrativo. Sólo eran pasibles de la excepción de inconstitucionalidad ${ }^{31}$, criterio fijado en 1915 por la Corte Suprema, para quien se aplicaba de preferencia, primero, la Constitución; después, la ley; y por último, las ordenanzas departamentales y los acuerdos municipales.

El primer fallo sobre la excepción de ilegalidad lo profirió el Consejo de Estado en 1941. Accedió a las pretensiones de la Texas Petroleum Company declarando inexequibles por ilegales los actos administrativos que rechazaron su propuesta de contrato sobre exploración y explotación de petróleos. El apoderado Rodríguez de Piñeres indicó en el concepto de la violación como vulnerado al art. 12 de la Ley 153 de 1887 y siguiendo a Bonnard sostuvo ${ }^{32}$ que los desbordamientos del acto reglamentario podían atacarse tanto por la excepción de ilegalidad como por el recurso de exceso de poder, siguiendo la diferenciación de la doctrina francesa de la

29 República de Colombia. Consejo de Estado. Sin sección. Sentencia (sin número) del día 20 de Septiembre de 1915. Consejero Ponente: Jesús Perilla. Sin radicación.

30 República de Colombia. Consejo de Estado. Sin sección. Sentencia (sin número) del día 16 de Diciembre de 1959. Consejero Ponente: Gabriel Rojas Arbeláez. Expediente 19591216.

31 República de Colombia. Consejo de Estado. Sin sección. Sentencia (sin número) del 16 de Julio de 1962. Consejero Ponente: Ricardo Bonilla Gutiérrez. Expediente 854:

"El hecho de que las ordenanzas sean obligatorias mientras no sean anuladas por la autoridad judicial, no quiere decir que deban ser aplicadas de preferencia a la Constitución o a la ley; cuando se suscitare alguna controversia sobre la aplicación de una ordenanza, que fuere contraria a la Constitución o a la ley, los funcionarios públicos deben observar el orden de preferencia así: primero, la Constitución; después, la ley; y por último, las ordenanzas departamentales $y$ los acuerdos municipales. (Sentencia de 26 de octubre de 1915. t. XXIV, p. 144)”.

32 Dijo:

"Por lo tanto, estos reglamentos pueden ser atacados utilizando el recurso por exceso de poder. La jurisprudencia del Consejo de Estado parece haber fijado ya definitivamente su criterio en tal sentido. Y lo mismo podrá, en casos idénticos, oponerse la excepción de ilegalidad.

/.../ Puesto que el reglamento formado en virtud de invitación del legislador permanece siendo un acto del Presidente de la República actuando como órgano administrativo, este reglamento es susceptible de ser atacado por las vías de recurso de que es susceptible todo acto del Presidente de la República actuando en tal cualidad, pudiendo oponérsele asimismo la excepción de ilegalidad.

En el mismo sentido se pronuncia Bonnard, en su obra Elementos de Derecho Público, al decir, como dice:

/.../ Il existe deux procedes pour attaquer l'illegalité d'un réglement. Ce sont l'exception d'illegalité devant les tribunaux judiciaires et le recours pour excés de pouvoir devant le Conseil $d^{\prime}$ Etat. Le premier procede aboutit au refus d'aplication du réglement illegal. Le second, a son annulation. Leur regime sera exposé plus loin, dans un des chapitres consacrés au contentieux administratif". 
excepción que se propone contra el reglamento en un proceso donde se cuestiona su interpretación -excepción de ilegalidad-, de aquél que se adelanta ante el Consejo de Estado discutiendo la valoración de su legalidad ${ }^{33}$-exceso de poder, el cual tiene dos límites: el interés en la legalidad que excluye al contencioso de plena jurisdicción y la existencia de recursos paralelos ${ }^{34}$-. La tesis fue que el Decreto 1270 se expidió por vía del ordinal 3 del art. 115 (C/1886) -más tarde art. 120, C/1886-y no por el ordinal 39, careciendo por tanto del carácter de ley formal.

La acción por excès de pouvair es objetiva -como nuestra acción de simple nulidad-pero - a diferencia nuestra- conserva un carácter personal porque en el siglo XIX l'Conseil d'État exigió al actor justificar la lesión de un derecho -arrêt Lebon, 1885-1894-, y luego bastó acreditar la lesión o amenaza a un interés (material, arrêt Cabanié, 4/12/1957; moral, arrêt Abbé Déliart, 8/2/1908; eventual, arrêt Despujol, 10/1/1930; retrospectivo, arrêt Delteil, 21/3/1958; y colectivo, arrêt Commune de Boisguillaume, 25/4/1941), constituyéndose por tanto en control directo en abstracto dirigido al acto administrativo, buscando su expulsión del ordenamiento.

A su vez la exception d'illégalité es de naturaleza subjetiva-similar a nuestra acción de nulidad y restablecimiento- siendo control indirecto particular y concreto que constituye un obstáculo momentáneo -inaplicación al caso concreto del reglamento con efecto inter partes- que interpone el demandado en cualquier

33 BONNARD, R. Précis de droit administratif: partie générale. Deuxième Édition. Paris. Librairie du Recueil Sirey (société anonyme). 1935, p. 256:

" $L$ 'exception d'illégalité peut être soulevée contre un règlement soit devant les tribunaux administratifs, soit devant les tribunaux judieiaires.

Dans ce dernier cas, la question se pose de savoir si et dans quelle mesure les tribunaux judiciaires sont compétents pour statuer par voie d'exception sur la légalité des règlements. II s'agit de savoir si l'exception de l'illégalité du règlement est une question préalable ou une question préjudicielle.

Ce point a déjà été examiné (cf. supra, p. 161). On a montré que l'exception d'illégalité du règlement est en principe pour les tribunaux judieiaires une question préjudicielle qui doit être portée devant les tribunaux administratifs, sauf dans le cas de l'artícle 471, 15', du Code pénal qui donne pouvoir aux tribunaux judiciaires d'apprécier la légalité des règlements lorsqu'il y a Iieu d'appliquer une sanction pénale à leur inobservation.

Le recours pour excès de pouvoir. - En ce qui eoneerne le recours pour excès de pouvoir contre les règlements du Chef de l'Etat, il s'est posé une question de recevabilité du recours pour certains de ces règlements.

Actuellement la jurisprudenee a décidé que le recours est recevable indistinctement contre tous les règlernents du Chef de l'Etat. Cette solution est parfaitement correcte.

En effet, si le règlement est un acte législatif au point de vue matériel, il est un acte législatif au point de vue organique. Or la recevabilité du recours pour excés de pouvoir est déterminée par le caractère organique de l'acte. II est recevable contre tous les actes des autorités administratives. (Cf. supra, p. 196). Les règlements présidentiels appartiennent bien à cette catégorie".

34 GARABOLDE, Ch. Le procédure tribunaux administratifs. Troisième Édition. París. Dalloz. 1981, p. 177. 
proceso con carácter intemporal -a diferencia de nuestra acción de nulidad y restablecimiento-: se gobierna por la regla quce temporalia sunt ad agendum, perpetua sunt ad excipiendum (arrêt Enziamini, 28/7/1951).

Al trasplantar la teoría, esta confusión en torno a los alcances en nuestro medio de las acciones y excepciones del derecho administrativo francés dio lugar, insuficientemente meditado el asunto, a que el Consejo de Estado terminara incorporando la excepción de ilegalidad como un simple concepto de apuntalamiento a la vía directa -la acción-, despojándola de toda eficacia.

Fijado el fundamento legal de la excepción de ilegalidad en el art. 12 de la Ley 153 de 1887, posición reiterada al año siguiente ${ }^{35}$, fue basamento para decidir una demanda contra los actos administrativos que negaron al Cónsul de Colombia en São Paulo (Brasil) el reconocimiento y pago de viáticos. En el petitum se estimó vulnerado el art. 12 de la ley 153 de 1887 y se argumentó en el concepto de la violación que el Decreto 1270 de 1939, en que se fundó la negativa, desbordó la potestad reglamentaria al ampliar las causales de prescripción de corto tiempo señaladas en el art. 2.542 del Código Civil. El Decreto carecía de carácter legislativo. Sólo era, concluyó el apoderado: “/.../ un simple decreto ordinario, que entraña desviación de poder, pues reformar las leyes es función privativa del legislador, y sólo excepcionalmente, y siempre por expresa autorización legislativa, del Órgano Ejecutivo"36.

Años más tarde algunos estimaron que el fundamento de la excepción de ilegalidad se encontraba en el art. 240 de la ley 4 de $1913^{37}$, norma que indicaba el orden de preferencia en caso de disposiciones contradictorias. Así lo evidencian unos alegatos de conclusión de un proceso en que se decidió la demanda contra el Ministerio de Guerra por negar el reconocimiento y pago de la prima mensual de alojamiento. El Consejo de Estado ${ }^{38}$ reiteró la opción por el art. 12 a pesar de que

35 República de Colombia. Consejo de Estado. Sin sección. Sentencia (sin número) del día 16 de Marzo de 1942. Consejero Ponente: Carlos Rivadeneira. Sin radicación.

36 República de Colombia. Consejo de Estado. Sin sección. Sentencia del día 5 de Octubre de 1948. Consejero Ponente: Jesús Estrada Monsalve. Sin radicación.

37 República de Colombia. Congreso de Colombia. Ley 4 del día 22 de Agosto de 1913 (sobre régimen político y municipal).

38 República de Colombia. Consejo de Estado. Sin sección. Sentencia del día 18 de Febrero de 1953. Consejero Ponente: Guillermo Acosta Acosta. Sin radicación:

"El doctor Rivera Villate, en su alegato presentado en esta instancia, para sustentar el recurso argumenta que el Decreto número 807 de 1952 en algunos de sus artículos y particularmente en el 4o, que sirve de base a la Resolución 1774, excede la potestad reglamentaria del Gobierno y modifica abiertamente la ley que pretende reglamentar, en forma que su aplicación al caso discutido contraría la doctrina contenida en los artículos 240 del Código de Régimen Político y Municipal y 12 de la Ley 153 de 1887.

En estas condiciones, la Corporación considera que el Decreto 807 de 1952 no es aplicable al caso de autos porque el artículo 12 de la Ley 153 de 1887 dispone que las órdenes y demás actos ejecutivos del Gobierno, expedidos en ejercicio de potestad reglamentaria, tienen fuerza obliga- 
se enjuició igualmente el art. 240. Años más tarde ${ }^{39}$ lo hizo de nuevo en un proceso en el que no se indicó como vulnerado el art. 12, aunque en verdad unos fallos fundamentaron en el art. $240^{40} \mathrm{y}$ otros en ambos ${ }^{41}$.

Lo cierto es que la aplicación de la excepción de ilegalidad no como medio exceptivo que se opone al derecho aducido -exceptio sine actioni agit- sino como concepto que apoya la pretensión del demandante determinó que en ocasiones su aplicación se solicitara como pretensión subsidiaria ${ }^{42}$. Y no es que se careciera de la oportunidad procesal para impetrarla como excepción ni en el Código Judicial (Ley 105 de 1931 ${ }^{43}$ ) ni en el Código Contencioso Administrativo (Ley 167 de 1941) porque ambos preceptos permitían presentar las excepciones que se opusieran a lo sustancial de la acción (arts. 341 y 109, respectivamente), entendiéndose por tal la excepción perentoria" : "la contraposición de un hecho extintivo, impeditivo o modificativo que excluya o atenúe los efectos jurídicos del hecho afirmado por el actor en el juicio" 45 que debía proponerse con la contestación de la demanda o alegarse en cualquiera de las instancias del juicio antes de la citación para sentencia (art. 341, Código Judicial). En estrictez no podría el Consejo de Estado tener a la excepción de ilegalidad como excepción porque siendo casi siempre la administración el sujeto pasivo de la relación jurídico-procesal, difícilmente podría excepcionar alegando la ilegalidad de su propio acto, como tampoco cuando fuese sujeto activo como en la acción de lesividad porque tal condición le impediría excepcionar.

Paradójico: por las razones anotadas, la única jurisdicción que no podría hacer uso de la "excepción" de ilegalidad es la todos dicen es la única que puede hacerlo y, el juez que no podría aplicarla es que todos afirman es el único facultado para ello.

El error persistió. El fallo de 2000 de la Corte Constitucional sobre el control de constitucionalidad de los arts. 12 y 240 lo evidencia: la Corte optó por fundamentar

toria y serán aplicados mientras no sean contrarios a la Constitución, a las leyes, ni a doctrina legal más probable".

39 República de Colombia. Consejo de Estado. Sin sección. Sentencia (sin número) del día 24 de Enero de 1967. Consejero Ponente: Alfonso Meluk. Sin radicación.

40 Por ejemplo, República de Colombia. Consejo de Estado. Sección Segunda. Sentencia del día 15 de Septiembre de 1977. Consejero Ponente: Samuel Buitrago Hurtado. Expediente 4.370.

${ }^{41}$ República de Colombia. Consejo de Estado. Sin sección. Sentencia (sin número) del día 20 de Junio de 1960. Consejero Ponente: Alejandro Domínguez Molina. Sin radicación.

42 República de Colombia. Consejo de Estado. Sección Tercera. Consejero Ponente: Carlos Betancur Jaramillo. Sentencia (sin número) del día 15 de Diciembre de 1977. Expediente 1.729.

43 República de Colombia. Congreso de Colombia. Ley 105 del 17 de Octubre de 1931 (sobre organización judicial y procedimiento civil).

44 República de Colombia. Consejo de Estado. Sin sección. Sentencia (sin número) del día 22 de Mayo de 1959. Consejero Ponente: Andrés Augusto Fernández. Expediente 0522.

45 República de Colombia. Consejo de Estado. Sin sección. Sentencia (sin número) del 9 de Febrero de 1951. Consejero Ponente: Guillermo Acosta Acosta. Sin radicación. 
la excepción de ilegalidad en el primero pero partió de un supuesto equivocado al omitir considerar que la razón para que el contencioso administrativo eligiera el art. 12 era que la fuerza obligatoria y aplicabilidad de las órdenes y demás actos ejecutivos del Gobierno se expidiera en ejercicio de la potestad reglamentaria ${ }^{46}$, ámbito de la excepción de ilegalidad y no, como supuso la Corte, que fueran obligatorios porque esta tenía otra fuente jurídica: el art. 193 (C/1886) que introdujo la obligatoriedad como regla general ${ }^{47}$.

Esta equivocación llevó a la Corte, tras fundamentar en el pluricitado art. 12, no sólo a declarar inexequible en él lo único que lo vinculaba con la excepción de ilegalidad -que los actos administrativos reglamentarios fuesen "expedidos en ejercicio de la potestad reglamentaria"- sino a rematar con este dislate que signó, en lo sucesivo, el empleo de la excepción de ilegalidad: "la llamada excepción de ilegalidad se circunscribe entre nosotros a la posibilidad que tiene un juez administrativo de inaplicar, dentro del trámite de una acción sometida a su conocimiento, un acto administrativo que resulta lesivo del orden jurídico superior". Ni que decir del que la Corte perdiera la oportunidad de estructurar una doctrina entorno a la función del poder judicial el Estado social de derecho, en perspectiva del principio de legalidad, como profundizador de la democracia tan necesaria hoy, al tener todo juez la facultad de declarar la excepción de ilegalidad, muy en la perspectiva de Bayon $^{48}$.

46 República de Colombia. Consejo de Estado. Sin sección. Sentencia (sin número) del día 5 de Octubre de 1948. Consejero Ponente: Jesús Estrada Monsalve. Sin radicación:

"con aplicación de la excepción de ilegalidad establecida en el artículo 12 de la Ley 153 de 1887, según la cual las órdenes y actos ejecutivos del Gobierno expedidos en ejercicio de la potestad reglamentaria sólo tienen fuerza obligatoria "mientras no sean contrarios a la Constitución, a las leyes ni a doctrina legal más probable”.

Se trata de una posición reiterada: República de Colombia. Consejo de Estado. Sección Tercera. Sentencia (sin número) del día 24 de Septiembre de 1973. Consejero Ponente: Alfonso Castilla Saiz. Expediente 1.167:

Sobre el particular la Sala considera que el Artículo 23 del Decreto 1902, en esta parte, se excedió y rebasó los límites de la potestad reglamentaria que la Constitución le asigna al Gobierno, pues hizo más gravosa la situación de los propietarios al exigírseles un requisito no previsto en la Ley, y de ahí que la Sala considere pertinente aplicar al caso de autos la excepción de ilegalidad prevista en el Artículo 12 de la Ley 153 de 1887 según el cual "los actos ejecutivos del Gobierno expedidos en ejercicio de la potestad reglamentaria tienen fuerza obligatoria y serán aplicados mientras no sean contrarios a las Leyes".

47 República de Colombia. Consejo de Estado. Sala de Consulta y Servicio Civil. Concepto (sin número) del día 26 de Noviembre de 1982. Consejero Ponente: Jaime Paredes Tamayo. Expediente 1.807:

"Es de advertir que como principio general del derecho público colombiano, que se deduce del artículo 193 de la Constitución, los actos administrativos son obligatorios y que solo pueden ser suspendidos o anulados por la jurisdicción de lo contencioso Administrativo".

48 BAYÓN, J. "Algunos comentarios sobre el papel del poder judicial en la transición a la democracia”. En: DOXA, Cuadernos de Filosofía del Derecho No. 30. 2007. Madrid. pp. 65-71. http:// 
¿Implica el desatino que la excepción de ilegalidad quedó sin fundamento? No, y no es necesaria norma expresa que la consagre como no la requiere la excepción de inconstitucionalidad -de hecho, a este momento solo hay una disposición en el ordenamiento jurídico colombiano que alude a ella: el art. 20 de la ley 393 de $1997^{49}$ - que se infiere del concepto de supremacía de la Constitución consagrado por su art. 4, norma que a juicio de la Corte no era posible tener como fundamento indirecto de la excepción de ilegalidad -si cualquier autoridad debe aplicar de manera prevalente los enunciados constitucionales sobre cualesquiera otros que le resulten contrarios, podría pensarse que de manera similar debe hacerlo respecto de la ley y las demás normas-, argumentando que como excepción al deber general de acatar el ordenamiento, la excepción de ilegalidad debe interpretarse de manera restringida y la aplicación analógica de disposiciones se guía por el aforismo de que frente a una misma razón de hecho procede una de derecho y no siempre la supremacía e integridad de la Constitución está en juego en la disconformidad de una norma inferior y otra superior.

La verdad es que la excepción de ilegalidad brota del principio de legalidad que si bien no tiene consagración expresa es supuesto por el sistema jurídico ${ }^{50}$, al punto de afirmarse que surge, "principalmente, del conjunto normativo contenido en los arts. 1, 2, 6, 121, 123. Inciso 2o., 124 de la C.P., pero así mismo tiene su raíz en las normas que a nivel constitucional han institucionalizado y regulado la jurisdicción de lo contencioso administrativo (arts. 236, 237-1-5-6 y 238)"51. Así, el ejercicio de la potestad reglamentaria se engasta en el principio de legalidad y excluye actuar sin vinculación a normas porque esta concreta el ejercicio de toda función pública (art. 121, C/1991) condicionando la existencia del empleo público (art. 122, C/1991), a la vez que funda la responsabilidad por su desconocimiento (arts. 6 y 90, C/1991) ${ }^{52}$.

Y de la misma manera que l'exception d'illégalité es en el derecho francés el anverso de la acción por l'excès de pouvair, término que engloba todas las formas de ilegalidad susceptibles de viciar al acto administrativo, la excepción de ilegalidad

descargas.cervantes virtual.com/servlet/SirveObras /24671175802130940700080/035285. pdf?incr=1 (consultado el día 7/01/2013).

49 República de Colombia. Congreso de Colombia. Ley 393 del día 29 de Julio de 1997 (por el cual se desarrolla el artículo 87 de la Constitución Política).

50 República de Colombia. Corte Constitucional. Sala Segunda de Revisión. Sentencia T-139 del día 22 de Marzo de 1994. Fundamento jurídico 3. M.P. Antonio Barrera Carbonell. Expediente T-23447.

51 República de Colombia. Corte Constitucional. Sala Plena. Sentencia C-513 del día 16 de Noviembre de 1994. Fundamento jurídico b. M.P. Antonio Barrera Carbonell. Expediente D-606.

52 República de Colombia. Corte Constitucional. Sala de revisión (sin identificación). Sentencia T-303 del día 1 de Julio de 1994. Fundamento jurídico c. M.P. Fabio Morón Díaz. Expediente $\mathrm{T}-32612$. 
lo es de la acción de nulidad, enderezada a garantizar el "principio de legalidad que es consustancial al Estado Social de Derecho que nuestra Constitución institucionaliza y se asegura el respeto y la vigencia de la jerarquía normativa"53; acción que inició con la ley 130 de 1913 que adoptó gran parte de la legislación española de 1888, instituyendo la acción de nulidad o "ciudadana" -y la privada para obtener la nulidad de los actos violatorios de derechos civiles, que sólo podía promover el titular- con el objeto de tutelar la legalidad objetiva de los actos administrativos de alcance nacional o local; luego lo hizo la ley 167 de 1941 -arts. 66 a 68- y más tarde el art. 85 del Decreto 01 de $1984^{54}$ y hora el art. 137 de la ley 1437 de $2011^{55}$.

Para sobreabundar en razones, la excepción de ilegalidad ni tiene ni requiere consagración expresa porque desde el momento en que se abandonó la concepción de la acción como elemento adjetivo del derecho material -ius perseguendi in iudicio- para concebirla como derecho público abstracto, individual y autónomo, modalidad de un derecho fundamental -de petición, indicó Couture ${ }^{56}$-, la acción adquirió la estirpe de derecho fundamental -tutela judicial efectiva, art. 229 (C/1991) - y su anverso, la excepción, linaje similar: reus in exceptione actor est -la excepción es, en cierto modo, la acción del demandado-. Siendo pues la excepción un poder jurídico del que se halla investido el demandado que lo habilita para oponerse a la acción promovida contra él, tiene al igual que la acción trasfondo próximo en los mencionados derechos fundamentales y remoto en otro derecho fundamental: la personalidad jurídica (art. 14, C/1991), del que brotan las potestades de la persona.

Fluye de lo expuesto que si bien la excepción de ilegalidad nace al amparo de la acción de nulidad en el contencioso administrativo no se encuentra referida exclusivamente a él: en tanto dispositivo -en términos de Agamben ${ }^{57}$ - que realiza el principio de legalidad puede y debe ser empleada en cualquier jurisdicción para

53 Corte Constitucional. Sala Plena. Sentencia C-513 del día 16 de noviembre de 1994 (citada).

54 República de Colombia. Presidencia de la República. Decreto 01 del día 2 de enero de 1984 (por el cual se reforma el Código Contencioso Administrativo).

55 República de Colombia. Congreso de Colombia. Ley 1437 del 18 de Enero de 2011 (por la cual se expide el Código de Procedimiento Administrativo y de lo Contencioso Administrativo).

56 COUTURE, E. Fundamento del derecho procesal civil. Tercera Edición. Buenos Aires. Ediciones De Palma. 1978, p. 74.

57 AGAMBEN, G. “¿Qué es un dispositivo?” En: Sociológica No. 73. 2011. México. Revista del Departamento de Sociología de la UNAM, pp. 249-264. http://www.revistasociologica. com. $\mathrm{mx} / \mathrm{pdf} / 7310 . p d f$, consultado el día 17/01/2013.

No es el momento para desarrollar esta noción en el ámbito del derecho que me encuentro explorando; baste citar el siguiente aparte del punto 6:

"Entonces, para otorgar una generalidad más grande a la clase de por sí vasta de los dispositivos de Foucault, llamo dispositivo a todo aquello que tiene, de una manera u otra, la capacidad de capturar, orientar, determinar, interceptar, modelar, controlar y asegurar los gestos, las conductas, las opiniones y los discursos de los seres vivos". 
oponerse a las consecuencias del acto administrativo reglamentario que se considere inválido, pidiendo su inaplicación al caso concreto.

Terminoestalínea expositiva mencionando que el fallodela Corte Constitucional ${ }^{58}$ produjo una interesante aclaración de voto cuestionando el fundamento normativo en el art. 12. Argumentó que la ordenación del sistema de fuentes inferido de él era un concepto derogado con la Constitución de 1991, afirmando la desaparición del principio de jerarquía kelseniano según el cual la importancia, el peso y la gradación dependen del lugar del órgano en la estructura. Para el efecto alegó que: i) la Constitución es norma normarum, ii) ella introduce un cambio estructural y cualitativo al consagrar principios y valores permeando el ordenamiento, iii) los principios democrático y participativo -pluralismo étnico, cultural y político- y de autonomía territorial reconfigura el sistema de las fuentes a partir de pluralismo normativo del art. 246 (C/1991), iv) las implicaciones que los ámbitos de lo estatal y lo jurídico sobre el objeto Constitución tiene la noción de Estado social de derecho y, v) además del Congreso, los jueces determinan las fuentes, con lo cual el bloque de constitucionalidad al incorporar tratados y convenios internacionales impacta el sistema jurídico complejizándolo.

\section{EL EMPLEO DE LA EXCEPCIÓN DE ILEGALIDAD: POSIBILIDADES DE UN TEST}

Establecido que la excepción de ilegalidad es una excepción de naturaleza especial -que aún debe ser suficientemente analizada- porque no nace directamente de los hechos que vinculan a las partes contendientes al litigio pero es aplicable a él por la incidencia del acto administrativo reglamentario en la litis en tanto se dirige a verificar su validez respecto de la ley reglamentada, queda por establecer la manera de emplearla, asunto del que se ocupa este capítulo.

El Consejo de Estado ${ }^{59}$ auscultando la nueva norma de la potestad reglamentaria -art. 189.11, C/1991- que mantuvo los tres elementos de la reglamentación limitándose a variar su orden -decretos, resoluciones y órdenes-, persistió en la doctrina expuesta en el contexto de la anterior Constitución y su límite en función a la necesidad de la cumplida ejecución de la ley. Dirigida la potestad reglamentaria, que salvo casos expresos ${ }^{60}$ corresponde al Presidente de la República sin necesidad de ley que

58 Corte Constitucional. Sala Plena. Sentencia C-037 del 26 de Enero de 2000, citada.

59 República de Colombia. Consejo de Estado. Sección Tercera. Sentencia (sin número) del día 3 de Diciembre de 2007. Consejera Ponente: Ruth Stella Correa Palacio. Expediente 11001-0326-000-2003-00014-01(24715) y otros, acumulados.

60 República de Colombia. Corte Constitucional. Sala Plena. Sentencia C-805 del día 1 de Agosto de 2001. Fundamento jurídico 4.2. M.P. Rodrigo Escobar Gil. Expediente OP-050:

".../ Se trata de ámbitos de regulación, que por expreso mandato de la Constitución se asignan a otros órganos Constitucionales, al margen de la potestad reglamentaria del Presidente. Tal 
lo determine porque su fin es el de fijar reglas específicas para que los distintos organismos del Estado cumplan adecuadamente las disposiciones legislativas, afirmó el Consejo de Estado que se trataba de una potestad ordinaria, derivada, limitada y permanente, a la vez que definió el reglamento como las normas generales dictadas por una autoridad distinta al órgano legislativo que tiene por fin asegurar la debida ejecución de las leyes y por potestad reglamentaria la ejercida con este propósito. Y concluyó con la Corte Constitucional ${ }^{61}$ que la potestad reglamentaria se caracteriza por ser una atribución constitucional inalienable, intransferible, inagotable e irrenunciable; atributo indispensable para que la administración encauce la ley hacia la operatividad efectiva en el plano de lo real. Es ordinaria porque la Constitución la adscribe a las funciones de la Rama Ejecutiva, tiene carácter derivado porque requiere la preexistencia de material legislativo, es limitada porque encuentra su límite y radio de acción en la Constitución y la ley sin poder alterar o modificar el contenido y el espíritu de la ley ni dirigirse a reglamentar leyes que no ejecuta la administración como tampoco reglamentar materias cuyo contenido está reservado al legislador, y por último, es permanente porque el Gobierno puede hacer uso de la misma tantas veces como lo considere oportuno, durante la vigencia de la ley ${ }^{62}$.

A diferencia de la potestad reglamentaría en la anterior Constitución, donde los Ministros carecían de ella ${ }^{63}$, se consideró que en la actual la tienen aunque de

es el caso del Consejo Superior de la Judicatura del Consejo, órgano al cual, de acuerdo con el artículo 257 de la Constitución, le corresponde, con sujeción a la ley "Dictar los reglamentos necesarios para el eficaz funcionamiento de la Administración de Justicia, los relacionados con la organización y funciones internas asignadas a los distintos cargos y la regulación de los trámites judiciales y administrativos que se adelanten en los despachos judiciales, en los aspectos no previstos por el legislador." Del mismo modo, el Consejo Nacional Electoral, de acuerdo con el artículo 265 de la Constitución, tiene, de conformidad con la ley, entre sus atribuciones especiales, la de "reglamentar la participación de los partidos y movimientos políticos en los medios de comunicación social del Estado." El Contralor General de la República, por su parte, tiene entre sus atribuciones, de acuerdo con el artículo 268 de la Constitución, las de "Prescribir los métodos y la forma de rendir cuentas los responsables del manejo de fondos o bienes de la Nación e indicar los criterios de evaluación financiera, operativa y de resultados que deberán seguirse." (Numeral $1^{\circ}$ ) y "Dictar normas generales para armonizar los sistemas de control fiscal de todas las entidades públicas del orden nacional y territorial." (Numeral 12). Al Contador General, funcionario de la Rama Ejecutiva, corresponde, a su vez, de acuerdo con el artículo 354 de la Constitución, “... determinar las normas contables que deben regir en el país, conforme a la ley." Del mismo modo, la Junta Directiva del Banco de la República ejerce las competencias de regulación que le corresponden de acuerdo con lo dispuesto en los artículos 371 y 372 de la Constitución".

61 República de Colombia. Corte Constitucional. Sala Plena. M.P. Alejandro Martínez Caballero. Sentencia C-028 del día 30 de Enero de 1997. Fundamento jurídico 6. Expediente OP-012.

62 República de Colombia. Corte Constitucional. Sala Plena. Auto 049 del día 20 de Febrero de 2008. Fundamento jurídico 3.2.1. M.P. Jaime Córdoba Triviño. Expediente D-7181.

63 República de Colombia. Consejo de Estado. Sección Primera. Sentencia (sin número) del día 25 de Enero de 1966. Consejero Ponente: Alfonso Arango Henao. Expediente 0125. 
manera residual y subordinada en la respectiva órbita competencial y recae, por lo general, en regulaciones técnicas $u$ operativas, e igualmente la tienen otras autoridades administrativas como las superintendencias ${ }^{64}$.

En las distintas jurisdicciones abundan actos administrativos reglamentarios de estas autoridades aplicables en juicios civiles y comerciales -piénsese en el universo de reglamentos del sector financiero- como también en materia de seguridad social.

En su interposición, la excepción de ilegalidad ataca el objeto litigioso -la pretensión- embistiendo el nacimiento del derecho alegado por el demandante que se apoya en la inobservancia del acto administrativo reglamentario por el demandado, lo que en estrictez no implica negarlo -hacerlo excluye la esencia de la excepción de fondo- sino cuestionar las condiciones de su génesis. Al proponerla deben verificarse, además de los límites generales y los especiales, los componentes del acto administrativo reseñados.

Si bien el control efectuado por el Consejo de Estado en 1941 sólo razonó sobre el órgano y la competencia del acto administrativo reglamentario, debe considerarse la materia y el contenido como lo puso en evidencia una sentencia en la que se dijo que la industria cinematográfica ya estaba gravada y no era posible imponerle el impuesto de industria y comercio previsto para los espectáculos públicos ${ }^{65}$.

La consideración del órgano, la competencia, la materia y el contenido del acto administrativo reglamentario respecto de la excepción de ilegalidad atendió al criterio de la concurrencia de los criterios formales y los materiales de predeterminación de las normas superiores a las inferiores: los dos primeros correspondían a los límites generales de la potestad reglamentaria y los dos últimos a los límites especiales de la materia a desarrollar: i) por el contenido de la ley en tanto esta al fijarlos circunscribe a ellos y ii) por la materia de la ley, en tanto que en derecho civil -el derecho privado contractual, la institución de la propiedad- o penal, la organización judicial y las normas procesales del ejercicio de los derechos en juicio son de competencia privativa de la ley pues su ejecución pertenece al ámbito jurisdiccional y no al administrativo ${ }^{66}$.

La infracción legal genérica se denomina violación de ley y se presenta cuando el acto administrativo reglamentario es contrario a disposiciones jerárquicamente superiores, creadores de situaciones jurídicas generales, separándose del texto o del espíritu por error respecto de los hechos sobre los cuales actúa. Se trata de vicios de forma en cuanto los actos administrativos deben formarse mediante procedimientos

64 República de Colombia. Consejo de Estado. Sección Primera. Sentencia (sin número) del día 24 de Agosto de 2000. Consejero Ponente: Juan Alberto Polo Figueroa. Expediente 6.096.

65 República de Colombia. Consejo de Estado. Sección Cuarta. Sentencia (sin número) del día 26 de Noviembre de 1982. Consejero Ponente: Enrique Low Murtra. Expediente 8.190.

66 República de Colombia. Consejo de Estado. Sin sección. Sentencia (sin número) del día 17 de Febrero de 1962 (citada). 
previstos en la ley, pues la forma es la regla general en el acto administrativo reglamentario, como en el acto jurídico privado lo es el intercambio del consentimiento.

Para determinar qué vicio de la forma afecta al acto administrativo reglamentario deben distinguirse tres categorías ${ }^{67}$ : a) las previas a su expedición, b) las concomitantes y c) las posteriores a su expedición. Y de estas sólo acarrea la inaplicación por excepción de ilegalidad las formas sustanciales, no las accidentales -formalidades insignificantes-. Como no existen las matemáticas jurídicas, son sustanciales, en cada caso concreto, las que constituyen una garantía y, por ende, un derecho para los asociados. Walline aconsejaba alguna vez preguntarse por el sentido de la decisión final si se hubieran seguido las formas legales dejadas de lado: ¿habría sido la misma o distinta a la establecida en el acto?

Igualmente debe verificarse que el acto administrativo reglamentario no contraríe los valores materiales del ordenamiento que recoge la ley reglamentada porque de hacerlo, la norma sería válida formalmente pero sustancialmente inválida, en cuanto la validez del neoconstitucionalismo incorpora valores materiales del ordenamiento.

Recordemos brevemente que en el año 1934 aparece Teoría pura del Derecho (Reine Rechtslehre) de Kelsen, escrito que recoge de manera más sistematizada las dos secciones que en torno a estática y dinámica jurídica había abordado en su obra de 1925 (Teoría general del Estado). Concibió al Estado como un orden coactivo de la conducta humana y buscó asegurar la unidad y formalización en las fuentes del derecho. La Reine Rechtslehre obedece a la idea del derecho como sistema jurídico y guarda en lontananza el componente ordine geométrico: la norma fundamente básica (Grundnorm) proporciona unidad a la pluralidad normativa ${ }^{68}$, fuente común y origen de la validez del sistema porque otorga competencia al primer legislador histórico. La Grundnorm en tanto norma presupuesta (vorausgesetzt), no creada por un acto real de voluntad de un órgano jurídico (gesetzt), es metajurídica ${ }^{69}$. Si la Grundnorm es una hipótesis básica ${ }^{70}$ presupuesta como válida, la validez que

67 República de Colombia. Consejo de Estado. Sección Primera. Sentencia (sin número) del día 25 de Mayo de 1968. Consejero Ponente: Alfonso Meluk. Expediente 19680525.

68 KELSEN, H. Teoría pura del derecho. Vigésima Segunda Edición. Buenos Aires. Editorial Universitaria de Buenos Aires. 1985 - p. 135.

69 KELSEN, H. Contribuciones a la Teoría pura del derecho. Cuarta Edición. México. Distribuciones Fontamara S.A. 1994 - p. 65:

"Yo he distinguido siempre claramente /.../ entre norma básica propuesta en el pensamiento jurídico como constitución en sentido lógico-jurídico, y la constitución en sentido jurídico-positivo, y siempre he insistido en que la norma básica en que la norma básica como constitución en sentido jurídico-positivo no es una norma de derecho positivo, no es una norma "puesta", es decir, creada por un acto real de voluntad de un órgano jurídico, sino una norma propuesta en el pensamiento jurídico".

70 KELSEN, Teoría pura del derecho, opus cit, p. 138. 
proporciona es objetiva (digamos formal), linaje que transmite al sistema que la tiene como fundamento. Esta validez corresponde a uno de los dos tipos de sistema (normativo ${ }^{71}$ y moral) que para Kelsen existen: el sistema dinámico en el que la Grundnorm proporciona una habilitación formal de creación de normas jurídicas en forma escalonada dada su construcción gradual (Stufenbau $)^{72}$, muy propia de la validez que empleamos en vigencia de la $\mathrm{C} / 86$, limitándonos a verificar órgano y competencia ${ }^{73}$-coherencia vertical-. La otra es la validez estática en que se miran contenidos, más empleada en los sistema morales.

Pero el neoconstitucionalismo inaugura una nueva economía en la validez: los contenidos -valores- (validez estática, en términos kelsenianos) adquieren relevancia. Se ha dicho que el sistema normativo constitucional contiene validez mixta (dinámica + estática) que cuestiona el recurso acrítico a valores del positivismo. La exigencia de unidad del sistema jurídico obliga a incorporar contenidos sustantivos de los valores. Ahora, por cuenta de lo que Guastini ${ }^{74}$ llamó la constitucionalización del ordenamiento jurídico, los valores al irradiarse al resto del ordenamiento por vía del preámbulo y su valor normativo indirecto o mediante valor normativo directo por su incorporación mediante estructuras normativas, puede tornar un acto administrativo reglamentario que en principio es formalmente válido en sustancialmente inválido, bien porque la ley lo era bien porque al desarrollarla colidió con valores superiores, siendo su efecto el de inaplicar el reglamento al caso concreto y así debe declararlo el juez ${ }^{75}$ quien no

71 Para el normativismo el derecho es un conjunto de normas; el concepto de norma jurídica ocupa un lugar central. Sobre la característica distintiva de la norma jurídica puede consultarse BULYGIN, E. y MENDONCA, D. Normas y sistemas normativos. Primera edición. Madrid. Marcial Pons, Ediciones Jurídicas y Sociales S.A. 2005.

72 KELSEN, Teoría pura del derecho, opus cit, p. 147:

"Un orden jurídico no es "un sistema de normas yuxtapuestas y coordinadas. Hay una estructura jerárquica y sus normas se distribuyen en diversos estratos superpuestos. La unidad del orden reside en el hecho de que la creación -y por consecuencia la validez-de una norma, está determinada por otra norma, cuya creación, a su vez, ha sido determinada por una tercera norma. Podemos de este modo remontarnos hasta la norma fundamental de la cual depende la validez del orden jurídico en su conjunto".

73 Ibídem, p. 113:

Si para comenzar nos limitamos al orden jurídico nacional podemos describir esquemáticamente su estructura jerárquica de la manera siguiente: de acuerdo con la norma fundamental, cuyo carácter hipotético ya hemos definido, el grado superior del derecho positivo es la Constitución, entendida en el sentido material de la palabra, cuya función esencial es la de designar los órganos encargados de la creación de las normas generales y determinar el procedimiento qué deben seguir. Estas normas generales forman lo que se denomina legislación.

74 GUASTINI, R. et al. "La "constitucionalización" del ordenamiento jurídico: el caso italiano". En Neoconstitucionalismos. Cuarta Edición. Madrid. Editorial Trotta. 2009 - p. 49.

75 República de Colombia. Corte Constitucional. Sala Séptima de Revisión. Sentencia T-362 del día 9 de Mayo de 2002. Fundamento jurídico 10. M.P. Eduardo Montealegre Lynet. Expediente T- 440808 . 
sólo debe interpretar el derecho positivo en clave constitucional sino adecuar su propio comportamiento a los mandatos constitucionales.

En este contexto la excepción de ilegalidad muestra su potencial de dispositivo de concreción de validez mixta constitucional en el proceso civil, comercial, laboral, penal o disciplinario, en cuanto contribuye a la materialización de los valores superiores del ordenamiento en perspectiva horizontal -efectos inter privatos de la Constitución- y reafirma el marco jurídico de un orden político, económico y social que tornan justo, al inaplicar en los casos concretos las normas del sistema jurídico que no cumplen con la exigencia. Al fin y al cabo, la Constitución en tanto orden jurídico fundamental de la comunidad requiere un específico orden jurídico: aquél que tiene un contenido recto y en tanto tal, legítimo; orden que no es preexistente sino que "tiene que ser creado, mantenido en vigor, conservado y desarrollado en cuanto orden histórico por medio de la actuación humana"76. La Constitución lo que en últimas garantiza es un orden jurídico moralmente recto ${ }^{77}$, habida cuenta que la idea de justicia es, por naturaleza, una idea política.

A lo expuesto hay que agregar que si el reglamento contra el que se interpone la excepción de ilegalidad en la oportunidad procesal prevista por el estatuto procesal recae en una actividad del régimen económico, por consagrar la Constitución un Estado interventor a través de un conjunto sistemático de disposiciones jurídicas (arts. 332 a 338, C/1991) destinadas a la realización de un orden económico y social justo (Preámbulo), se deben respetar las razones de conveniencia invocadas. Así, la excepción de ilegalidad exige una mayor carga argumentativa porque en esta materia opera el criterio de la inconstitucionalidad manifiesta ${ }^{78}$. Para el efecto, el modelo económico al que se dirige el reglamento tiene como límites los valores materiales del ordenamiento superior, en tanto logran su dimensión normativa incorporándose en cualquier estructura normada como los principios - que ya no corresponden a la idea decimonónica que de ellos se tenía ${ }^{79}$ o los derechos fundamentales. En consecuencia, oponer la excepción de ilegalidad implica acreditar que el reglamento vulnera: i) derechos fundamentales, ii) claros mandatos constitucionales o iii) establece una regulación manifiestamente irrazonable o desproporcionada ${ }^{80}$.

76 HESSE, C. Escritos de derecho Constitucional. Primera Edición. Madrid. Centro de Estudios Constitucionales. 1983 - p. 15.

77 HESSE, C. et al. “Constitución y derecho Constitucional”. En, Manual de derecho Constitucional. Segunda Edición. Madrid. Marcial Pons, Ediciones Jurídicas y Sociales. 2001 - p. 5.

78 República de Colombia. Corte Constitucional. Sala Plena. Sentencia C-265 del día 2 de Junio de 1994. Fundamento jurídico 5. Consejero Ponente: Alejandro Martínez Caballero. Expediente D-464.

79 RUIZ, M. Sistemas jurídicos y conflictos normativos. Primera Edición. Madrid. Editorial Dykinson. 2002 - p. 104.

80 República de Colombia. Corte Constitucional. Sala Plena. Sentencia C-074 del día 25 de Febrero de 1993. Fundamento jurídico 1. M.P. Ciro Angarita Barón. Expediente D-119. 
En materia penal y disciplinaria la manera como el acto administrativo reglamentario y con él la posibilidad de cuestionar su validez mediante la excepción de ilegalidad se inserta es a través del tipo en blanco o abierto o de reenvío, técnica legislativa de integración del tipo. Considerando los alcances de una certificación de la Superintendencia Bancaria sobre la tasa de usura, la Corte Suprema ${ }^{81}$ dijo que debía acudirse a un precepto del mismo ordenamiento para integrar a plenitud la conducta y realizar la adecuación típica, "amén de establecer, entre otros factores, por ejemplo, la conciencia de la antijuridicidad, razón por la cual, no se viola el principio de reserva cuando el legislador señala los elementos básicos para delimitar la prohibición y remite a otras instancias el complemento correspondiente, siempre que este sea claro y permita establecer sin equívocos la conducta punible y su sanción". En los tipos en blanco, continúa la Corte Suprema, suelen distinguirse: a) el núcleo esencial que incumbe exclusivamente al legislador, el cual contiene los elementos básicos de la conducta punible, la correspondiente punibilidad y el reenvío expreso o tácito a otro precepto y b) el complemento, donde se sitúa propiamente el acto administrativo reglamentario, el cual especifica las condiciones -penal o extrapenal-, siempre que tenga carácter general y sea expedido con competencia. El núcleo y el complemento integran una sola disposición y se sujetan a las exigencias del principio de legalidad: existencia previa a la comisión de la conducta punible, señalamiento de los elementos estructurales del núcleo o la sanción corresponde al legislador y, tanto el núcleo como el complemento deben ser claros, ciertos e inequívocos.

En todo caso, precisó la Corte Constitucional ${ }^{82}$, "esas descripciones penales son constitucionalmente válidas, siempre y cuando el correspondiente reenvío normativo permita al intérprete determinar inequivocamente el alcance de la conducta penalizada y de la sanción correspondiente", y requieren para integrar el tipo configurando unidad normativa el núcleo básico delimitado por el legislador y el complemento ${ }^{83}$ : remisión precisa, previa a la conducta, la norma complemento de conocimiento público y contener principios y valores constitucionales.

81 República de Colombia. Corte Suprema de Justicia. Sala de Casación Penal. Sentencia (sin número) del día 12 de Diciembre de 2005. Magistrada ponente Marina Pulido de Barón. Expediente 23.899.

82 República de Colombia. Corte Constitucional. Sala Plena. Sentencia C-559 del día 4 de Agosto de 1999. Fundamento jurídico 5. M.P. Alejandro Martínez Caballero. Expediente D-2297. Para un análisis detenido de la figura de los tipos penales en blanco y el reenvío dinámico para obtener su complemento con otros ordenamientos jurídicos o administrativos, el ilustrativo salvamento parcial de voto de Eduardo Montealegre Lynett en Corte Constitucional. Sala Plena. Sentencia C-333 del día 29 de Marzo de 2001, M.P. Rodrigo Escobar Gil. Expediente D3189.

83 República de Colombia. Corte Constitucional. Sala Plena. Sentencia C-605 del día 1 de Agosto de 2006. Fundamento jurídico 6. M.P. Marco Gerardo Monroy Cabra. Expediente D-6180. 


\section{Conclusión}

Encontrado el error en el tratamiento de la excepción de ilegalidad y reconstruidas sus características operativas he bosquejado una propuesta de alcance como dispositivo del principio de legalidad en los procesos civiles, comerciales, laborales, penales, disciplinarios y administrativos de naturaleza jurisdiccional, proveyendo un fundamento que permite su empleo en esta jurisdicciones, a fortiori que la norma que se tuvo hasta ahora como su cimiento desapareció o por el control otorgado al Consejo de Estado en vigencia de la Constitución de 1886, o por la extinción y/o dificultades del principio de jerarquía kelseniano o por la inexequibilidad del aparte que lo ligaba con la excepción de ilegalidad.

\section{REFERENCIAS}

\section{Doctrina}

AGAMBEN, G. “¿Qué es un dispositivo?” En: Sociológica No. 73. 2011. México. Revista del Departamento de Sociología de la UNAM - pp. 249-264. http://www. revistasociologica. com.mx/pdf/7310.pdf, consultado el día 17/01/2013.

ARAGÓN, M. Sobre las nociones de supremacía y supralegalidad Constitucional. Primera Edición. Bogotá. Universidad Externado. Editorial de la Universidad. 1986.

BAYÓN, J. "Algunos comentarios sobre «el papel del poder judicial en la transición a la democracia". En, DOXA, Cuadernos de Filosofía del Derecho No. 30. 2007. Madrid. pp. 65-71. http://descargas.cervantesvirtual.com/servlet/ SirveObras/24671175802130940700080/035285.pdf?incr=1 (consultado el día 7/01/2013).

BONNARD, R. Précis de droit administratif: partie générale. Deuxième Édition. Paris. Librairie du Recueil Sirey (société anonyme). 1935.

CHARRY, J. La excepción de inconstitucionalidad. Primera Edición. Bogotá. Ediciones Jurídicas Radar. 1994.

COUTURE, E. Fundamento del derecho procesal civil. Tercera Edición. Buenos Aires. Ediciones De Palma. 1978.

GARABOLDE, Ch. Le procédure tribunaux administratifs. Troisième Édition. París. Dalloz. 1981.

GUASTINI, R. et al. "La 'constitucionalización' del ordenamiento jurídico: el caso italiano". En Neoconstitucionalismos. Cuarta Edición. Madrid. Editorial Trotta. 2009.

HESSE, C. Escritos de derecho Constitucional. Primera Edición. Madrid. Centro de Estudios Constitucionales. 1983. 
et al. "Constitución y derecho Constitucional". En, Manual de derecho Constitucional. Segunda Edición. Madrid. Marcial Pons, Ediciones Jurídicas y Sociales. 2001.

KELSEN, H. Contribuciones a la Teoría pura del derecho. Cuarta Edición. México. Distribuciones Fontamara S.A. 1994.

Teoría pura del derecho. Vigésima Segunda Edición. Buenos Aires. Editorial Universitaria de Buenos Aires. 1985.

NIETO, A. "Estudio preliminar". En, BALADIEZ, M. Validez y eficacia de los actos administrativos. Primera Edición. Madrid. Marcial Pons, Ediciones Jurídicas. 1994.

República de Colombia. Corte Constitucional, Sala Plena. Sentencia C-037 del 26 de Enero de 2000. Magistrado ponente Vladimiro Naranjo Mes. Expediente D 2441.

ROJAS, D. “¿Abolida la excepción de ilegalidad?” En, en Pensamiento Jurídico No. 12. 2000. Bogotá. Revista de la Universidad Nacional, Facultad de Derecho, Ciencias Políticas y Sociales. Editorial de la Universidad.

RUIZ, M. Sistemas jurídicos y conflictos normativos. Primera Edición. Madrid. Editorial Dykinson. 2002.

VIDAL, J. Derecho Administrativo. Decima Primera Edición. Editorial Temis. Bogotá. 1997.

\section{Jurisprudencia}

República de Colombia. Consejero de Estado. Sin sección. Sentencia (sin número) del día 19 de Agosto de 1955. Consejero Ponente: Ildefonso Méndez. Sin radicación.

República de Colombia. Consejo de Estado. Sala de Consulta y Servicio Civil. Concepto (sin número) del día 26 de Noviembre de 1982. Consejero Ponente: Jaime Paredes Tamayo. Expediente 1.807.

República de Colombia. Consejo de Estado. Sección Cuarta. Sentencia (sin número) del día 13 de Diciembre de 1976. Consejero Ponente: Jorge Dávila Hernández. Expediente 4.608.

República de Colombia. Consejo de Estado. Sección Cuarta. Sentencia (sin número) del 24 de Mayo de 1973. Consejero Ponente: Miguel Lleras Pizarro. Expediente 2.226.

República de Colombia. Consejo de Estado. Sección Cuarta. Sentencia (sin número) del día 26 de Noviembre de 1982. Consejero Ponente: Enrique Low Murtra. Expediente 8.190.

República de Colombia. Consejo de Estado. Sección Primera. Sentencia (sin número) del día 31 de Septiembre de 1966. Consejero Ponente: Alberto Hernández Mora. Sin radicación. 
República de Colombia. Consejo de Estado. Sección Primera. Sentencia (sin número) del día 25 de Enero de 1966. Consejero Ponente: Alfonso Arango Henao. Expediente 0125.

República de Colombia. Consejo de Estado. Sección Primera. Sentencia (sin número) del día 24 de Agosto de 2000. Consejero Ponente: Juan Alberto Polo Figueroa. Expediente 6.096.

República de Colombia. Consejo de Estado. Sección Primera. Sentencia (sin número) del día 25 de Mayo de 1968. Consejero Ponente: Alfonso Meluk. Expediente 19680525.

República de Colombia. Consejo de Estado. Sección Segunda. Sentencia (sin número) del día 15 de Septiembre de 1977. Consejero Ponente: Samuel Buitrago Hurtado. Expediente 4.370.

República de Colombia. Consejo de Estado. Sección Segunda. Sentencia del día 15 de Septiembre de 1977. Consejero Ponente: Samuel Buitrago Hurtado. Expediente 4.370.

República de Colombia. Consejo de Estado. Sección Tercera. Consejero Ponente: Carlos Betancur Jaramillo. Sentencia (sin número) del día 15 de Diciembre de 1977. Expediente 1.729.

República de Colombia. Consejo de Estado. Sección Tercera. Sentencia (sin número) del día 24 de Septiembre de 1973. Consejero Ponente: Alfonso Castilla Saiz. Expediente 1.167.

República de Colombia. Consejo de Estado. Sección Tercera. Sentencia (sin número) del día 3 de Diciembre de 2007. Consejera ponente Ruth Stella Correa Palacio. Expediente 11001-03-26-000-2003-00014-01(24715) y otros, acumulados.

República de Colombia. Consejo de Estado. Sin sección. Auto (sin número) del día 22 de Marzo de 1963. Consejero Ponente: Carlos Gustavo Arrieta. Sin radicación.

República de Colombia. Consejo de Estado. Sin sección. Sentencia (sin número) del día 14 de Junio de 1961. Consejero Ponente: Carlos Gustavo Arrieta. Sin radicación.

República de Colombia. Consejo de Estado. Sin Sección. Sentencia (sin número) del día 30 de Octubre de 1964. Consejero Ponente: Carlos Gustavo Arrieta. Expediente 1.524.

República de Colombia. Consejo de Estado. Sin sección. Sentencia (sin número) del 12 de Abril de 1962. Consejero Ponente: Guillermo González Charry. Sin radicación.

República de Colombia. Consejo de Estado. Sin sección. Sentencia (sin número) del 22 de Marzo de 1963. Consejero Ponente: Carlos Gustavo Arrieta. Sin radicación. 
República de Colombia. Consejo de Estado. Sin sección. Sentencia (sin número) del día 30 de Agosto de 1963. Consejero Ponente: Carlos Gustavo Arrieta. Sin radicación.

República de Colombia. Consejo de Estado. Sin sección. Sentencia del día 13 de Noviembre de 1962. Consejero Ponente: Gabriel Rojas Arbeláez. Expediente 2.132.

República de Colombia. Consejo de Estado. Sin sección. Sentencia (sin número) del día 28 de Junio de 1963. Consejero Ponente: Carlos Gustavo Arrieta. Sin radicación.

República de Colombia. Consejo de Estado. Sin sección. Sentencia del día 14 de Noviembre de 1962. Consejero Ponente: Carlos Gustavo Arrieta. Sin radicación.

República de Colombia. Consejo de Estado. Sin sección. Sentencia del día 10 de Octubre de 1962. Consejero Ponente: Carlos Gustavo Arrieta. Sin radicación.

República de Colombia. Consejo de Estado. Sin sección. Sentencia (sin número) del día 17 de Febrero de 1962. Consejero Ponente: Carlos Gustavo Arrieta. Sin radicación.

República de Colombia. Consejo de Estado. Sin sección. Sentencia (sin número) del día 20 de Septiembre de 1915. Consejero Ponente: Jesús Perilla. Sin radicación.

República de Colombia. Consejo de Estado. Sin sección. Sentencia (sin número) del día 16 de Diciembre de 1959. Consejero Ponente: Gabriel Rojas Arbeláez. Expediente 19591216.

República de Colombia. Consejo de Estado. Sin sección. Sentencia (sin número) del 16 de Julio de 1962. Consejero Ponente: Ricardo Bonilla Gutiérrez. Expediente 854

República de Colombia. Consejo de Estado. Sin sección. Sentencia (sin número) del día 16 de Marzo de 1942. Consejero Ponente: Carlos Rivadeneira. Sin radicación.

República de Colombia. Consejo de Estado. Sin sección. Sentencia del día 5 de Octubre de 1948. Consejero Ponente: Jesús Estrada Monsalve. Sin radicación.

República de Colombia. Consejo de Estado. Sin sección. Sentencia del día 18 de Febrero de 1953. Consejero Ponente: Guillermo Acosta Acosta. Sin radicación.

República de Colombia. Consejo de Estado. Sin sección. Sentencia (sin número) del día 24 de Enero de 1967. Consejero Ponente: Alfonso Meluk. Sin radicación.

República de Colombia. Consejo de Estado. Sin sección. Sentencia (sin número) del día 20 de Junio de 1960. Consejero Ponente: Alejandro Domínguez Molina. Sin radicación.

República de Colombia. Consejo de Estado. Sin sección. Sentencia (sin número) del día 22 de Mayo de 1959. Consejero Ponente: Andrés Augusto Fernández. Expediente 0522. 
República de Colombia. Consejo de Estado. Sin sección. Sentencia (sin número) del 9 de Febrero de 1951. Consejero Ponente: Guillermo Acosta Acosta. Sin radicación.

República de Colombia. Consejo de Estado. Sin sección. Sentencia (sin número) del día 5 de Octubre de 1948. Consejero Ponente: Jesús Estrada Monsalve. Sin radicación.

República de Colombia. Consejo de Estado. Sin secciones. Sentencia (sin número) del día 14 de Abril de 1942. Consejero Ponente: Diógenes Sepúlveda Mejía. Sin radicación.

República de Colombia. Corte Constitucional. Sala de revisión (sin identificación). Sentencia T-303 del día 1 de Julio de 1994. Fundamento jurídico c. Magistrado ponente Fabio Morón Díaz. Expediente T-32612.

República de Colombia. Corte Constitucional. Sala Plena. Auto 049 del día 20 de Febrero de 2008. Fundamento jurídico 3.2.1. Magistrado ponente Jaime Córdoba Triviño. Expediente D-7181.

República de Colombia. Corte Constitucional. Sala Plena. Magistrado ponente Alejandro Martínez Caballero. Sentencia C-028 del día 30 de Enero de 1997. Fundamento jurídico 6. Expediente OP-012.

República de Colombia. Corte Constitucional. Sala Plena. Sentencia C-513 del día 16 de Noviembre de 1994. Fundamento jurídico b. Magistrado ponente Antonio Barrera Carbonell. Expediente D-606.

República de Colombia. Corte Constitucional. Sala Plena. Sentencia C-805 del día 1 de Agosto de 2001. Fundamento jurídico 4.2. Magistrado ponente Rodrigo Escobar Gil. Expediente OP-050.

República de Colombia. Corte Constitucional. Sala Plena. Sentencia C-265 del día 2 de Junio de 1994. Fundamento jurídico 5. Consejero Ponente: Alejandro Martínez Caballero. Expediente D-464.

República de Colombia. Corte Constitucional. Sala Plena. Sentencia C-074 del día 25 de Febrero de 1993. Fundamento jurídico 1. Magistrado ponente Ciro Angarita Barón. Expediente D-119.

República de Colombia. Corte Constitucional. Sala Plena. Sentencia C-559 del día 4 de Agosto de 1999. Fundamento jurídico 5. Magistrado ponente Alejandro Martínez Caballero. Expediente D-2297.

República de Colombia. Corte Constitucional. Sala Plena. Sentencia C-333 del día 29 de Marzo de 2001. Magistrado ponente Rodrigo Escobar Gil. Salvamento parcial de voto, Magistrado disidente Eduardo Montealegre Lynett. Expediente D3.189. 
República de Colombia. Corte Constitucional. Sala Plena. Sentencia C-605 del día 1 de Agosto de 2006. Fundamento jurídico 6. Magistrado ponente Marco Gerardo Monroy Cabra. Expediente D-6180.

República de Colombia. Corte Constitucional. Sala Segunda de Revisión. Sentencia T-139 del día 22 de Marzo de 1994. Fundamento jurídico 3. Magistrado ponente Antonio Barrera Carbonell. Expediente T-23447.

República de Colombia. Corte Constitucional. Sala Séptima de Revisión. Sentencia T-362 del día 9 de Mayo de 2002. Fundamento jurídico 10. Magistrado ponente Eduardo Montealegre Lynet. Expediente T- 440808.

República de Colombia. Corte Suprema de Justicia. Sala de Casación Penal. Sentencia (sin número) del día 12 de Diciembre de 2005. Magistrada ponente Marina Pulido de Barón. Expediente 23.899. 